\title{
RESPIRATORY INFECTIONS IN INFANTS' WARDS *
}

\author{
WALTER F. CHAPPELL, M.D., AND ALAN BROWN, M.D. \\ NEW YORK
}

The subject of ward infections in children's hospitals has long been one of discussion from the standpoint of contagious diseases, while the infectious nature of the respiratory affections has received little attention until recently. In the wards of the Babies' Hospital it is not measles, whooping-cough or scarlet fever that is feared, but rather the pncumococeus and streptococcus infections, both of which may be said to be omnipresent. In fact it seems evident that if we could prevent the respiratory infections, which begin as simple rhinitis or pharyngitis and frequently end in bronchopneumonia, we could save a much larger number of feeding cases (marasmus babies).

During the past two years we had 129 instances of acute nasopharyngeal infections in our feeding wards and not one single case of measies, whooping-cough or scarlet fever. During this same period we have lost from uncomplicated marasmus but twenty-nine out of 271 marasmus babies treated, while of the total deaths, ninety-seven in number, two-thirds were due to complications, chiefly respiratory.

\section{INCREASE OF RESPIRATORY AFFECTIONS}

A striking change seen in the last fifteen years in the Babies' Hospital has been the reduction in the proportion of intestinal diseases from 36 per cent. of the total admissions to 13 per cent., and an increase of severe acute respiratory infections from 8 per cent. to 17 per cent. This is only further evidence that the intestinal diseases are being prevented in the city at large, while the respiratory infections are not. Nothing in the hospital service is more discouraging than the development of acute nasopharyngitis, otitis, laryngitis, bronchitis and bronchopneumonia in infants admitted for other conditions. In fact, these infections are more serious than the common contagious diseases and are always more difficult to control, because the source of infection and manner of spreading are less obvious.

The following table shows the number, variety and mortality of the acute infections of the respiratory tract met with in 271 feeding cases, under treatment in two seasons:

* Submitted for publication March 5, 1914.

* From the Babies' Hospital, New York. 


\begin{tabular}{|c|c|c|}
\hline & Number & $\begin{array}{l}\text { Mortality, } \\
\text { Per Cent. }\end{array}$ \\
\hline Bronchopneumonia $\ldots \ldots \ldots \ldots \ldots$ & 29 & 84 \\
\hline Otitis $\ldots \ldots \ldots \ldots \ldots \ldots \ldots \ldots$ & 63 & 60 \\
\hline Diphtheria $\ldots \ldots \ldots \ldots \ldots \ldots \ldots \ldots \ldots$ & 11 & 54 \\
\hline Bronchitis $\ldots \ldots \ldots \ldots \ldots \ldots \ldots \ldots$ & 4 & 75 \\
\hline Adenitis $\ldots \ldots \ldots \ldots \ldots \ldots \ldots$ & 4 & 0 \\
\hline Meningitis $\quad \ldots \ldots \ldots \ldots \ldots \ldots \ldots \ldots \ldots$ & 3 & 100 \\
\hline Senticemia ioniv) & 3 & 67 \\
\hline Nasopharyngitis (simple) & 2 & 50 \\
\hline
\end{tabular}

This table is not intended to convey the impression that the infants in every case died as a direct result of the complications, but rather that these infections played a large part in the final issue. In many instances they were the direct cause of death. Bronchopneumonia in these patients has an exceedingly high mortality, owing to their feeble resistance, while meningitis was always fatal.

The following table illustrates the relative frequency of the infection by months:

\begin{tabular}{|c|c|c|}
\hline Month & $\begin{array}{l}\text { Number of } \\
\text { Infections }\end{array}$ & $\begin{array}{l}\text { Percentage of Total } \\
\text { To. of Infections }\end{array}$ \\
\hline January $\ldots \ldots \ldots \ldots \ldots$ & 14 & 10.8 \\
\hline February $\ldots \ldots \ldots \ldots \ldots \ldots$ & 16 & 12.4 \\
\hline March $\ldots \ldots \ldots \ldots \ldots \ldots$ & 14 & 10.8 \\
\hline April $\ldots \ldots \ldots \ldots \ldots \ldots$ & 13 & 10.0 \\
\hline May..$\ldots \ldots \ldots \ldots \ldots$ & 5 & 3.8 \\
\hline June $\ldots \ldots \ldots \ldots \ldots \ldots$ & 3 & 2.3 \\
\hline July $\ldots \ldots \ldots \ldots \ldots$ & 7 & 5.4 \\
\hline August $\ldots \ldots \ldots \ldots \ldots \ldots$ & 2 & 1.5 \\
\hline September $\ldots \ldots \ldots \ldots \ldots \ldots$ & 4 & 3.1 \\
\hline October $\ldots \ldots \ldots \ldots \ldots \ldots$ & 14 & 10.8 \\
\hline November $\ldots \ldots \ldots \ldots \ldots \ldots$ & 10 & 7.7 \\
\hline December $\ldots \ldots \ldots \ldots \ldots \ldots$ & 17 & 13.1 \\
\hline
\end{tabular}

A somewhat similar chart compiled by L. F. Meyer in Berlin shows a corresponding frequency of ward infections during the fall and winter months in comparison with the warm season.

It has been a rather striking observation that the degree of susceptibility to infection varies directly with the length of residence in the institution. The arerage stay in the hospital for 271 feeding cases was 46.4 days, in those developing infections 57.3 days and in those developing more than one infection 65 days. It is worthy of note that one infection readily predisposes to the development of another. Out of 129 respiratory infections there were sixty-nine cases with only one infection, twenty-eight with two infections, and two cases with three infections. This last point has been further illustrated by Meyer, who showed that after the second week of hospital residence the infections gradually increased from 0.25 per cent. to 3.08 per cent. at the end of 100 days.

The following histories serve to illustrate what occurs throughout the year in working with these delicate infants: 
CASE I.-B. I., aged 7 months, weight $3,850 \mathrm{gm}$. For the four weeks following admission weight was practically stationary; during this period the infant had signs of a general bronchitis with a leukocytosis. Not until all signs had disappeared and the temperature had become normal did the infant begin to gain (Chart 1).

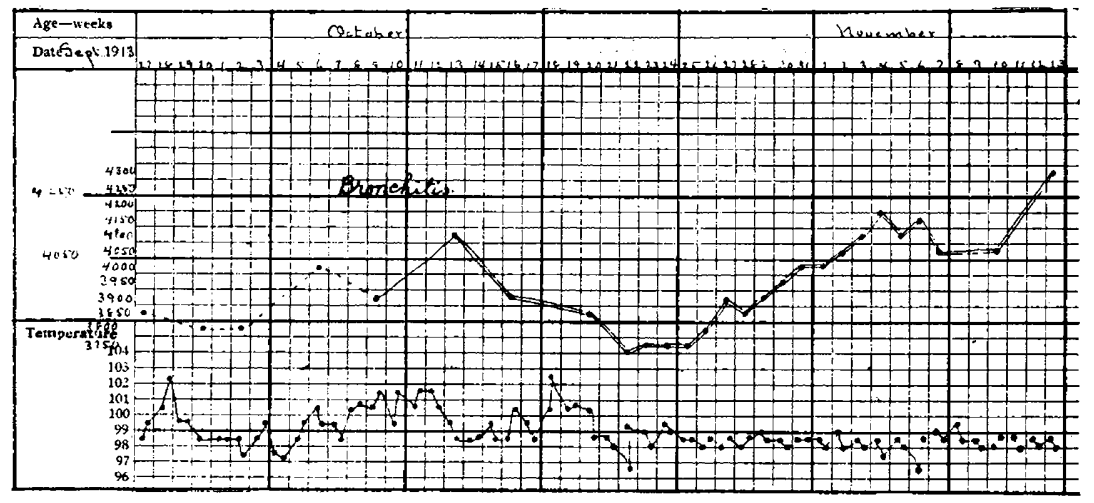

Weight and Temperature Chart of Case 1.

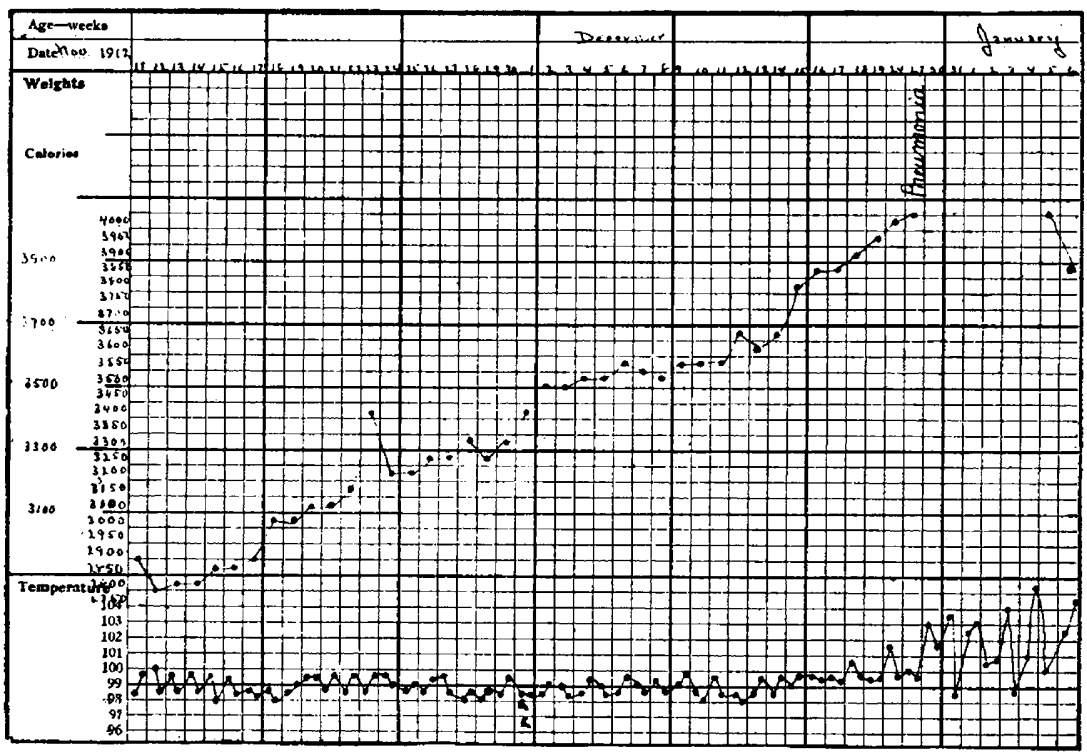

Weight and Temperature Chart of Case 2.

CASE 2.-M. S., aged 21/2 months, weight $2,900 \mathrm{gm}$., gained $1,600 \mathrm{gm}$. in six weeks. Developed a bronchopneumonia and died in seven days (Chart 2 ).

CASE 3.-S. W., aged 11 days, weight $3,025 \mathrm{gm}$., after having been in the hospital six weeks and gained 825 gm., developed streptococcus meningitis and died in two days (Chart 3 ).

CAE 4.-P. M., aged two weeks, weight $2,350 \mathrm{gm}$. On two successive occasions developed a blood infection due to the pneumococeus and staphylococcus 
aureus. Both these invasions were unattended with definite clinical symptoms save the slight weight and temperature disturbance. During the last infection he had a few furuncles.

\section{TYPES OF INFECTION}

As previously mentioned in this paper, it is the pneumococcus and streptococcus infections that cause most of the trouble. Some idea of

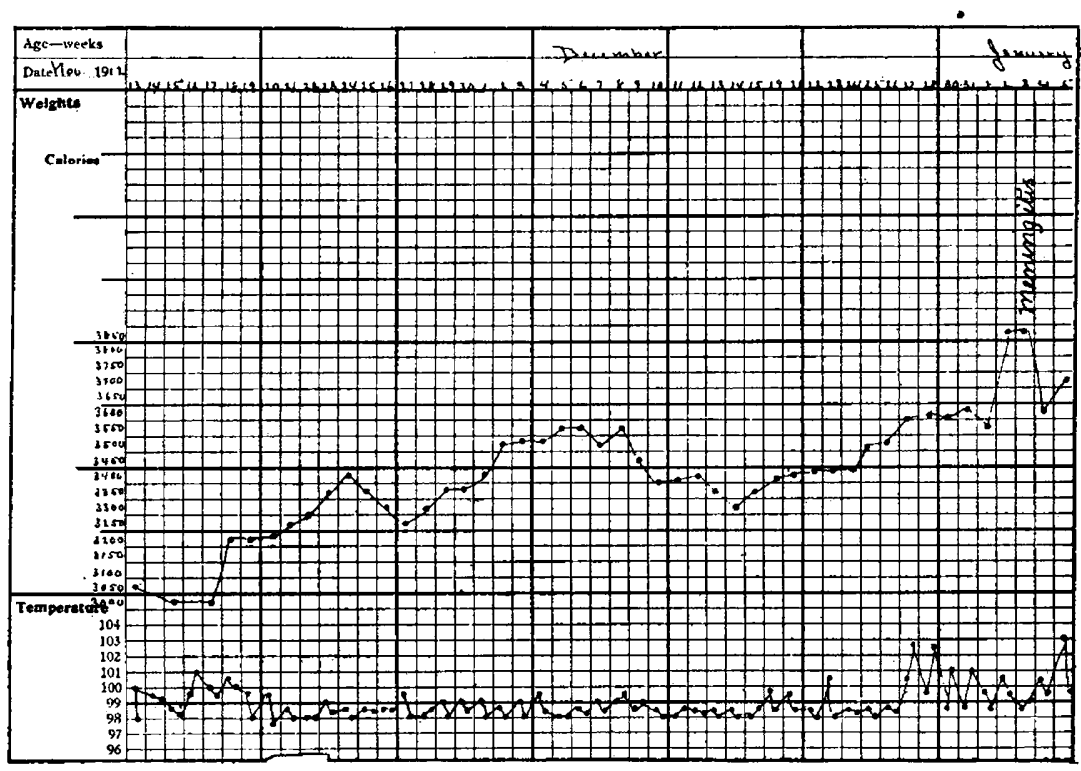

Weight and Temperature Chart of Case 3.

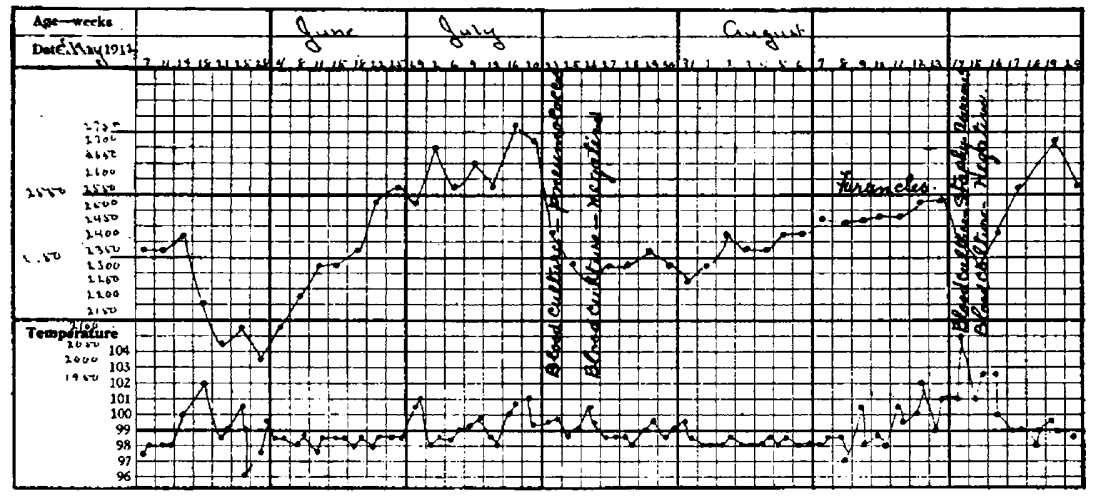

Weight and Temperature Chart of Case 4.

the frequency with which these and other organisms are present in respiratory infections may be obtained from the results of a series of cultures made from the bronchial secretions of these infants. Altogether 619 sputum cultures have been made during the past three years in the 
Babies' Hospital, and of these, 71 per cent. showed the presence in varying numbers of the pneumococcus, 42 per cent. the staphylococcus, and 31 per cent. the influenza bacillus. The staphylococcus was present in 85 per cent. of the cultures made and is the organism most frequently found in these infections. The variation in the organisms present may be seen in the following table, showing very little change from year to year:

A.-Jan. 31, 1911 to May 31, 1911 B.-Oct. 1, 1911, to May 31, 1912 C.-Oct. 1, 1912, to April 6, 1913

$\begin{array}{cc}\text { Pneumo- } & \text { Strepto- } \\ \text { coccus } & \text { coccus } \\ \text { Per Cent. } & \text { Per Cent. }\end{array}$

69

82

77

\section{B. Influenzae Per Cent.}

32

33

28

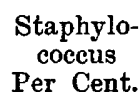

Per Cent.

76

89

90

An examination of eighty-six cultures made from the pus after paracentesis of one or both ears of the infants gave the following results:

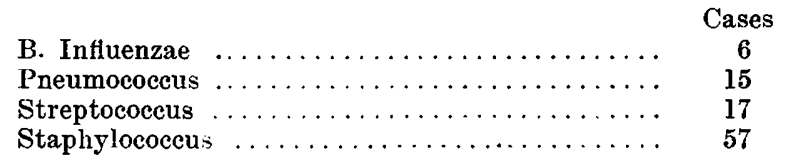

In a comparative study of cultures made from the sputum and nasopharynx some three years ago by Dr. Wollstein, at the Babies' Hospital, it was found that there was no essential difference in the variety of organisms in these different localities. If the pneumococcus was found in the nose and nasopharynx it was invariably present in the sputum culture. Apparently, these organisms are not limited to any special location in respiratory infections.

\section{METHOD OF TRANSMISSION}

It has long been believed that the common contagious diseases, scarlet-fever, diphtheria, whooping-cough, measles, small-pox, mumps and rubella are to a large extent communicated by aerial transmission. Of late, considerable experimental and clinical evidence gathered from abroad and in America has been brought forward to show that this is not the case. To Grancher of Paris is due the credit for first putting into practice prophylactic measures based on the assumption that infection was by contact. From his methods the plan has been developed of segregating the contagious diseases by means of separate stalls or cubicals, etc., and treating different types in the same ward with the assistance of aseptic nursing. Some disregard air separation; others aim to interrupt, partially or wholly, air exchange between compartments occupied by patients. All, however, seek to establish physical separation and to 
prevent contact. The adequacy of these methods has been demonstrated both in Europe and in this country.

In respiratory infections, however, this plan does not offer anything like such a uniform success as has been obtained in the contagious diseases mentioned; if it were so, our problem would be much more simple.

Concerning the pneumococcus and streptococcus, the possibility of aerial transmissions seems greater, and to date there is lacking sufficient evidence to prove that such transmission does not occur.

During the past year there have been made in the Babies' Hospital some observations on ward atmosphere which bear on this point. Petriplates with blood-agar media, were exposed in the wards when the air was quiet and during sweeping with sawdust dampened with 1 to 2,000 mercuric chlorid. At sweeping times the number of organisms in the air was greatly increased.

In every instance the plates were exposed five minutes. It is rather interesting to note that in the premature ward where the floor is wiped with damp cloths and where special care is taken to exclude every infant and every attendant suffering from any form of infection, there were usually found but one to two colonies. On one occasion, however, a number of colonies of pneumococcus were found. Two days later one of the premature infants developed a fatal pneumococcus meningitis.

\section{PROPHYLAXIS}

It is unnecessary to discuss measures of respiratory prophylaxis previously proposed, especially as regards the use of hexamethylenamin. None of these procedures have so far met with success. The use of hexamethylenamin as a respiratory antiseptic has been shown by Burnham to be valueless. The doses in which it can be given are not sufficient to exert any bactericidal action, and furthermore, the ability to be excreted as formaldehyd varies with the individual. Much that has been claimed for it was without justification.

Wollstein and Meltzer from their experiments on the production of pneumonia in animals by insufflation have reached the conclusion that the organisms enter from the upper respiratory passages and gradually find their way into the smaller bronchi where they multiply in this enclosed space and produce the lesions typical of pneunonia. They also showed that organisms injected into the blood do not produce pneumonia, but, on the other hand, they may be recovered from the blood in five hours after their introduction by insufflation. These observations are rather interesting from the clinical standpoint when one considers how frequently from a pneumonia patient one may obtain a history of a previous head cold. It has seemed to us that these observations suggest that prerentive measures would give beneficial results in the treatment of all 
ward cases. We will now pass to an account of our own attempt to prevent respiratory ward infections.

1. Increasing the child's individual resistance by careful attention to its nutrition.

2. By careful nursing for the purpose of minimizing the danger of transmitting infection.

3. By the direct prevention of the respiratory infections by postnasal douching.

The first of these measures has received our constant attention, while the second is almost an impossibility where nurse-maids do the greater part of the handling of patients. The third has been the object of our special study during the six months from January, 1913, to June, inclusive, and was undertaken from the experience of one of us (Chappell) in the treatment of colds, influenza and various infections of the upper respiratory tract for the past fifteen years. This treatment is postnasal douching with warm antiseptic solutions, chiefly boric acid, followed by argyrol solutions of various strengths. The cleansing of the nasopharynx of all mucus and food-remains, which form a good culture medium for the development of the various organisms, seems very desirable as a preventive measure in these cases.

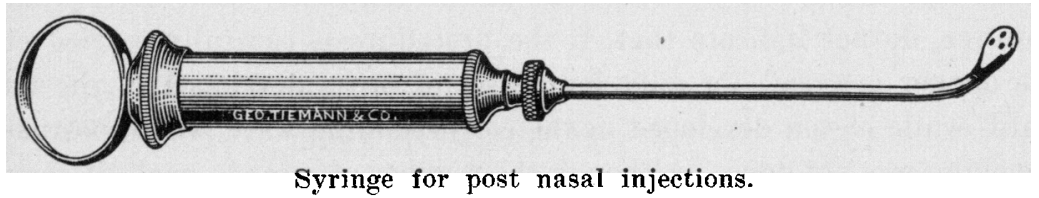

'I'wo wards, A and B, were taken during the above period; forty patients were treated in each ward. In both these wards the floor was swept each morning with sawdust dampened with 1 to 2,000 mercuric chlorid solution, and each ward fumigated once a month. So far as could be carried out, no discrimination between types of babies admitted to the above-mentioned wards was made. Our only difference in treatment was that in Ward B, postnasal douching was carried out immediately on the patient's admission and subsequently twice a week.

The postnasal syringe used (Fig. 5) was devised by one of us (Chappell) and was of the same pattern as one used for older children and adults. It was, however, made much smaller. The syringe is made of metal having a capacity of 6 c.c. The openings at the tip of the syringe are arranged so that the fluid is directed upward, forward and backward, but not laterally, thus minimizing the risk of the entrance of fluid into the eustachian tubes. The advantages of the syringe are as follows: (1) The small quantity of solution used does not put any extra pressure in the naso-pharynx; (2) the small curve makes it rery easy to 
pass behind the curtain of the soft palate and cannot produce any traumatism, nor does it require great skill in its use; (3) the openings in the tip are on the anterior and posterior surfaces, and a transverse slit on the end with no lateral openings.

The infant is wrapped tightly in a sheet and held in a sitting posture on the lap of a nurse. While depressing the tongue the syringe is carefully introduced behind the soft palate in such a manner that the tip is held free in the postnasal space; the contents are then quickly discharged, the solution pouring out of both nostrils, mingled with curds and mucus. As soon as the contents of the syringe have been evacuated the nurse quickly throws the infant's head forward, in this manner facilitating the expulsion of mucus, etc. The crying of the infant has been found to be an advantage, since it aids in the more thorough cleansing of the nostrils. Occasionally, streaks of blood are obtained. This was more frequently seen when the infant had adenoids and was apparently due to the slight traumatism of the syringe, and did not occur when more experience was gained. In those patients in whom small amounts of blood accompanied the douching, no ill effects followed, either immediate or remote.

The chief objection urged against postnasal douching is the possibility of the introduction of fluid into the eustachian tubes. Our observations, however, do not indicate that, if the procedure is carefully carried out, the danger is great, for only four cases of otitis developed in the trial ward, while eleven developed in the corresponding ward where postnasal douching was not done. Although the number of cases is small, it should be considered that during this period over 400 postnasal douches were administered to infants; yet in private practice, on older patients many thousands of postnasal douches have been given by us without the development of any aural symptoms. It seems from this experience that the postnasal douching so far from being a cause of acute otitis, was in reality a valuable prophylactic measure. Throughout the period of obserration the ears of all patients were carefully watched, even when no symptoms were present. A reduction in the number of pneumonias was also noted.

In totalling all the infections for the six months in Wards A and B, it was found that in Ward $\mathbf{A}$ there were fifty-seven infections and in Ward B (douching) only twenty-seven, a reduction of 50 per cent. The results can be more readily seen in the following table:

Total patients treated $\ldots \ldots \ldots \ldots \ldots$

No. of infections present on admission

No. of infections developing in hospital

$\begin{array}{cc}\text { Ward A } & \begin{array}{c}\text { Ward B } \\ \text { (Prophylactic } \\ \text { douching). }\end{array} \\ 40 & 40 \\ 10 & 11 \\ 27 & 27\end{array}$


It is worth mention that in Ward B there developed two patients with retropharyngeal abscess and in Ward A there were none; whether the use of the postnasal syringe was a factor in these cases it is impossible to state.

During the six months of observation we used first a 1 per cent. boracic acid solution, followed immediately by a 1 per cent. argyrol solution. Of course, these solutions undoubtedly acted only as a wash; they certainly were not bactericidal, as cultures were made to ascertain this fact. More recently we have been employing undiluted hydrogen peroxid. The injection of this is followed by a solution composed of three quarters normal saline and one quarter Seiler's solution, with results that have appeared better than were obtained with the milder solutions. A larger experience is necessary to determine whether these stronger solutions are preferable to the milder ones. The fact that otitis has frequently been attributed to the use of peroxid has received our special attention. So far, ninety-six douches have been given in Ward B and no case of otitis has developed; while in Ward A, where none of the children received the douche, four cases have developed.

Cultures have been made before and after douching with peroxid and bacterial counts made from the washings of the postnasal space with sterile water. We have not been able to come to any conclusions on this point from the fact that the counts varied considerably and the reduction, when it did occur, was not sufficient to warrant definite conclusions.

The treatment by postnasal douching is now being continued by other observers at the Babies' Hospital and the results obtained so far confirm our reports. 